\title{
Mathematical Analysis of the Implication of the Proposed Rise in the Retirement Age on the Unemployment Situation in Nigeria
}

\begin{abstract}
By Abayomi Ayoade ${ }^{*}$ Rotimi Folaranmi ${ }^{ \pm} \&$ Tolulope Latunde
The population of Nigeria as of today stands at about 200,000,000. The economically active or working population (15-64 years) increased from 111.1 million in 2017 to 115.5 million in 2018. The unemployment rate accordingly, rose from $18.8 \%$ in 2017 to $23.1 \%$ in 2018. The situation has aggravated poverty and brought about untold hardship particularly for the unemployed. Currently, there is intense debate regarding the adjustment in the statutory age of retirement in Nigeria. To that end, a deterministic compartmental mathematical model is designed to study the implication of the proposed increase in the national statutory age of retirement on the national output and the trend of unemployment in Nigeria. The mathematical interpretation of the compartments of the model leads to the corresponding first-order ordinary differential equations. The resulting equations are proved to satisfy the basic features of a good mathematical model. The unemployment-free equilibrium is derived and the stability analysis is performed via stability theory of nonlinear differential equations. Numerical simulation is conducted to validate the analytical results. Results from the simulation show that increasing the national statutory age of retirement will limit the rate at which individuals are moving from the unemployed state to the employed state but widen the rate at which individuals are joining and remaining in the unemployed state.
\end{abstract}

Keywords: Poverty, Retirement, Model, Unemployment rate, Simulation

\section{Introduction}

Unemployment is a major problem in Nigeria and other Third World that have a similar economic structure with Nigeria. Unemployment is an economic and social disorder which arises as a result of the imbalance between supply and demand in the labour market and sometimes aggravated by the population's growth. The unemployed class of a population can be said to be the proportion of the population who are able and desire to work but, as a result of inadequate demand, are unable to secure jobs. Usually, unemployment is a terrible social condition since a proportion of the population battles to endure the least welfare and consumption level. The labour force of a country is the sum of employed and unemployed individuals in the country. The age bracket for labour force varies from one country to another and from one profession to another profession. For example, in Nigeria, the statutory retirement age for professors and judges is 70

\footnotetext{
*Lecturer II, Department of Mathematics, University of Lagos, Nigeria.

${ }^{ \pm}$Lecturer II, Department of Mathematical and Computing Sciences, KolaDaisi University, Nigeria.

tLecturer II, Department of Mathematics, Federal University Oye-Ekiti, Nigeria.
} 
years while it is 65 years for other academic staff in tertiary institutions. The statutory retirement age drops to 60 years for teachers in both secondary and elementary schools. However, the labour force in Nigeria generally encompasses all individuals aged 15-64 years who desire to work irrespective of whether they secure jobs or not.

The population of Nigeria currently stands at about 200,000,000 with a growth rate of $2.62 \%$ in 2018 . The economically active population is more than $50 \%$ of the total population with the figure of $115,500,000$ of which $26,680,500$ are unemployed as at December 2018 (National Bureau of Statistics-NBS 2018). The situation has aggravated poverty and made life difficult in Nigeria. The rapid growth rate of the population has also exacerbated the unemployment rate. Currently, there is intense debate regarding the adjustment in the statutory age of retirement. Some individuals and organisations have been calling for rising in the statutory age of retirement which some state governments in Nigeria have yielded to. For instance, the Ondo state government of Nigeria has announced an increase in the statutory age of retirement for workers of her tertiary institutions in May 2019. The State government approved 70 years for professors as the new retirement age and 65 years for other staff of her tertiary institutions. The unemployment rate has been rising in Nigeria over the years. Table 1 shows the trend of the unemployment rate and quarterly change in 2015-2018 in Nigeria.

Table 1. Unemployment Rate and Quarterly Change in 2015-2018

\begin{tabular}{|l|c|c|}
\hline Period & Unemployment rate (\%) & Rate of quarterly change (\%) \\
\hline $2015 \mathrm{q} 1$ & 7.54 & 0.65 \\
\hline $\mathrm{q} 2$ & 8.19 & 1.71 \\
\hline $\mathrm{q} 3$ & 9.9 & 0.54 \\
\hline $\mathrm{q} 4$ & 10.44 & 1.64 \\
\hline $2016 \mathrm{q} 1$ & 12.09 & 1.24 \\
\hline $\mathrm{q} 2$ & 13.32 & 0.56 \\
\hline $\mathrm{q} 3$ & 13.88 & 0.35 \\
\hline $\mathrm{q} 4$ & 14.23 & 0.21 \\
\hline $2017 \mathrm{q} 1$ & 14.44 & 1.74 \\
\hline $\mathrm{q} 2$ & 16.18 & 2.62 \\
\hline $\mathrm{q} 3$ & 18.8 & 1.62 \\
\hline $\mathrm{q} 4$ & 20.42 & 1.41 \\
\hline $2018 \mathrm{q} 1$ & 21.83 & 0.92 \\
\hline $\mathrm{q} 2$ & 22.73 & 0.4 \\
\hline $\mathrm{q} 3$ & 23.13 & \\
\hline
\end{tabular}

Source: NBS 2018.

The aim of this paper is to use mathematical modelling method to investigate the implication of the proposed increase in the national statutory age of retirement on the national production and the current trend of unemployment in Nigeria. 


\section{Literature Review}

X-raying the available literature on the subject, we start from 2011 when Misra and Singh (2011) designed a model of unemployment based on the previous work of Nikolopoulos and Tzanetis (2003). Nikolopoulos and Tzanetis (2003) developed a model taking into consideration the allocation of houses for a homeless population induced by a natural disaster, described in terms of a system of nonlinear ordinary differential equations with three variables -employed individuals, unemployed individuals, and temporary workers. Misra and Singh (2011) analysed the equilibria of their proposed model, applying the stability theory, and conducted some numerical simulations, revealing that the unemployment struggle might need urgent interventions: they predicted that the unemployment rate might rise continuously and, if the peak was reached then it would be difficult to overcome in future.

Misra and Singh (2013) also came out with an empirical work when they substituted the temporarily employed variable with newly created vacancies incorporating a delayed feature in their previous study of Misra and Singh (2011). Another model of unemployment was also formulated by Sirghi et al. (2014) based on the system of differential equations with distributed time delay. Besides, they discovered that the unemployment level was signal to the employers to hire labourers at low wages. The separation of the available vacancies into government and current created vacancies was a major modification to the earlier works of Misra and Singh (2011) and Misra and Singh (2013) by Harding and Neamtu (2018). Harding and Neamtu adopted the idea of Misra and Singh (2011) and Misra and Singh (2013), modifying the earlier efforts by formulating an unemployment model in which job searches are open to both migrant and native workers.

In the same way, by taking into account the previously mentioned works, Munoli and Gani (2016) attempted to examine an optimal control policy for unemployment considering two possible interventions: government policies, designed to provide jobs directly to unemployed individuals, and government policies, designed to create new vacancies. The situation in Munoli and Gani (2016) of the labour market was governed by three first order ordinary differential equations, pointing to variation in vacancies available and unemployed/employed, quite similar to Misra and Singh (2013). Inspired by the work of Munoli and Gani (2016), Galindro and Torres (2018) proposed an unemployment model and applied optimal control to investigate the appropriate policies for avoiding unemployment in Portugal. Kazeem, Alimi and Ibrahim (2018) designed an unemployment model and derived a threshold quantity for the control of unemployment. They discovered that the unemployment solution in Nigeria was a function of selfemployment as academic certificates cannot bring food on the table. El Fadily and Kaddar (2019) also developed a model to monitor labour force evolution and discovered the phenomenon of co-existence of both active unemployed and employed populations. They explained the phenomenon of co-existence of the two populations in terms of the fact that job seekers occur relatively quickly because of population growth. 
A good number of factors can shape unemployment situation apart from statutory age of retirement. For example, Aminu (2019) opined that there was mismatch between the university training and the needs of the labour market which gave birth to education-job mismatch in Nigeria. Also, Teixeira et al. (2020) argued that Brazilian workers were influenced by the government programmes as to the length of stay in the job which might have the tendency of enhancing the low incentive for companies to invest in human capital, encouraging turn over in the Brazilian labour market and generating the average low productivity of the national workers. Unemployment has negative impacts on the general well-being and the economy of a nation. The links between unemployment, poverty and economic growth in Nigeria was investigated by Adelowokan et al. (2019). The authors discovered that while unemployment had a positive and significant relationship with poverty at the conventional level, it had a negative and important relationship with growth. The result of the study of Adelowokan and co researchers (2019) was corroborated by the outcome of the study conducted by Yasin and Gachunga (2019) where a negative long run relationship was established between unemployment and economic growth in Kenya. In an attempt to substantiate the negative impact of unemployment on societal stability, Amin (2019) formulated a mathematical model of crime and unemployment to conduct a study on the relationship between crime and unemployment. The researcher established a rapid increase in the volume of crime as the unemployment rises. While the mathematical studies of unemployment are exhaustive in the literature, we are not aware of the one that is directed to the implication of an increase in the age of retirement with reference to the unemployment situation in Nigeria.

\section{Methodology}

The global rise in unemployment rate due to the enormous upsurge in world population prompted Munoli and Gani (2016) to formulate a mathematical model that captured an unemployment environment with an optimal control strategy for the deterministic unemployment model. The model is made up of three first-order ordinary differential equations, with the employed $(E)$, unemployed $(U)$ and the vacancies $(V)$ as the state variables:

$$
\left.\begin{array}{l}
\frac{d U(t)}{d t}=\pi-\kappa U(t) V(t)-\alpha_{1} U(t)+\gamma E(t), \\
\frac{d E(t)}{d t}=\kappa U(t) V(t)-\alpha_{2} \mathrm{E}(t)-\gamma E(t), \\
\frac{d V(t)}{d t}=\alpha_{2} \mathrm{E}(t)+\gamma E(t)-\delta \mathrm{V}(\mathrm{t})+\phi
\end{array}\right\}
$$

The interpretation for the state variables and parameters of Eq. (1) is presented in Table 2 . 
Table 2. Variables/Parameters Description

\begin{tabular}{|c|c|}
\hline Variables/Parameters & Meaning \\
\hline$U(t)$ & Population of the unemployed at time $t$ \\
\hline$E(t)$ & Population of the employed at time $t$ \\
\hline$V(t)$ & Available vacancies at time $t$ \\
\hline$\pi$ & Recruitment rate into $U(t)$ \\
\hline$\kappa$ & $\begin{array}{l}\text { Rate at which unemployed individuals are becoming } \\
\text { employed }\end{array}$ \\
\hline$\alpha_{1}$ & Rate of migration and death of unemployed individuals \\
\hline$\alpha_{2}$ & Rate of retirement and death of employed individuals \\
\hline$\gamma$ & Rate at which individuals are fired from their present job \\
\hline$\phi$ & Rate at which new vacancies are created \\
\hline$\delta$ & Rate of reduction in vacancies due to recession \\
\hline
\end{tabular}

Source: Munoli and Gani (2016).

The necessary and sufficient conditions for the attainment of optimal control of the proposed unemployment problem with the efficient use of implemented strategies to create employment to the unemployed individuals and to provide new vacancies were derived and analysed by Munoli and Gani (2016). However, the implication of the adjustment in the statutory age of retirement in creating employment for the unemployed and in generating new vacancies was not considered by the authors. It is against this backdrop that the present study attempts to extend the model to investigate the implication of the proposed rise in the statutory age of retirement on the current unemployment situation in Nigeria. As unemployment and underemployment coexist simultaneously in Nigeria, the possibility of the increase in the population of the unemployed due to the influx of those who leave their current employment as a result of lack of job satisfaction without immediate hope of securing the satisfactory employment and the newly created vacancies due to the action is considered. Also, following the idea of Galindro and Torres (2018), the rate at which employment is being created is considered. If the rate at which individuals leave their current jobs as a result of lack of job satisfaction is $\beta$ and the rate at which the employment is created is $\omega$ then the system of Eq. (1) becomes

$$
\left.\begin{array}{l}
\frac{d U(t)}{d t}=\pi-\kappa U(t) V(t)-\alpha_{1} U(t)+\gamma E(t)+\beta E(\mathrm{t}), \\
\frac{d E(t)}{d t}=\kappa U(t) V(t)-\alpha_{2} \mathrm{E}(t)-\gamma E(t)-\beta E(\mathrm{t})+\omega, \\
\frac{d V(t)}{d t}=\alpha_{2} \mathrm{E}(t)+\gamma E(t)+\beta E(\mathrm{t})-\delta \mathrm{V}(\mathrm{t})+\phi
\end{array}\right\}
$$

The variables and parameters interpretations for Eq. (2) together with their values and sources are presented in Table 3. 
Table 3. Variables/Parameters Description, their Values and Sources

\begin{tabular}{|c|c|c|c|}
\hline Variables/Parameters & Meaning & Values & Sources \\
\hline$U(t)$ & As in Table 2 & 10000 & $\begin{array}{c}\text { Munoli and Gani } \\
\text { (2016) }\end{array}$ \\
\hline$E(t)$ & As in Table 2 & 1000 & $\begin{array}{l}\text { Munoli and Gani } \\
\text { (2016) }\end{array}$ \\
\hline$V(t)$ & As in Table 2 & 100 & $\begin{array}{l}\text { Munoli and Gani } \\
\text { (2016) }\end{array}$ \\
\hline$\pi$ & As in Table 2 & 5000 & $\begin{array}{c}\text { Munoli and Gani } \\
\text { (2016) }\end{array}$ \\
\hline$\kappa$ & As in Table 2 & $\begin{array}{c}0.00000 \\
9\end{array}$ & $\begin{array}{l}\text { Munoli and Gani } \\
\text { (2016) }\end{array}$ \\
\hline$\alpha_{1}$ & As in Table 2 & 0.04 & $\begin{array}{c}\text { Munoli and Gani } \\
\text { (2016) }\end{array}$ \\
\hline$\alpha_{2}$ & As in Table 2 & 0.05 & $\begin{array}{c}\text { Munoli and Gani } \\
\text { (2016) }\end{array}$ \\
\hline$\gamma$ & As in Table 2 & 0.001 & $\begin{array}{c}\text { Munoli and Gani } \\
\text { (2016) }\end{array}$ \\
\hline$\phi$ & As in Table 2 & 0.007 & $\begin{array}{l}\text { Munoli and Gani } \\
\text { (2016) }\end{array}$ \\
\hline$\delta$ & As in Table 2 & 0.005 & Assumed \\
\hline$\beta$ & $\begin{array}{c}\text { Rate at which people } \\
\text { leave their jobs due to job } \\
\text { dissatisfaction }\end{array}$ & 0.0001 & Assumed \\
\hline$\omega$ & $\begin{array}{l}\text { Rate of employment } \\
\text { creation }\end{array}$ & 0.0002 & Assumed \\
\hline
\end{tabular}

Theorem 1: The solutions of the system of Eq. (2) exist and are unique in $\mathfrak{R}^{3}$. Suppose the system of Eq. (2) is represented as

$$
\begin{aligned}
& f_{1}=\pi-\kappa U(t) V(t)-\alpha_{1} U(t)+\gamma E(t)+\beta E(t) \\
& f_{2}=\kappa U(t) V(t)-\alpha_{2} \mathrm{E}(t)-\gamma E(t)-\beta E(t)+\omega \\
& f_{3}=\alpha_{2} \mathrm{E}(t)+\gamma E(t)+\beta E(t)-\delta V(t)+\phi
\end{aligned}
$$

then, let $D$ denotes the region

$\left|\mathrm{t}-\mathrm{t}_{0}\right| \leq \mathrm{a},\left\|\mathrm{x}-\mathrm{x}_{0}\right\| \leq \mathrm{b}, \mathrm{x}=\left(x_{1}, x_{2}, \cdots, x_{n}\right), \mathrm{x}_{0}=\left(x_{10}, x_{20}, \cdots, x_{n 0}\right)$,

and suppose that $f(t, x)$ satisfies the Lipschitz condition

$\left\|\left(\mathrm{t}, \mathrm{x}_{1}\right)-\mathrm{f}\left(\mathrm{t}, \mathrm{x}_{2}\right)\right\| \leq \mathrm{k}\left\|\mathrm{x}_{1}-\mathrm{x}_{2}\right\|$.

Whenever the pairs $\left(t, \mathrm{x}_{1}\right)$ and $\left(t, x_{2}\right)$ belong to $D$, where $k$ is a positive constant, then, there is a constant $\delta>0$ such that there exists a unique continuous vector solution $x(t)$ of the system in the interval $t-t_{0} \leq \delta$. It is important to note that the 
condition is satisfied by requirement that $\frac{\partial f_{1}}{\partial x_{j}}, i=1,2, \ldots$ be continuous and bounded in $D^{1}$

Proof:

We now return to our model Eq. (3) - Eq. (5). We are interested in the region $0 \leq \alpha \leq \mathfrak{R}$.

We look for a bounded solution in this region and whose partial derivatives satisfy $\delta \leq \alpha \leq 0$, where $\alpha$ and $\delta$ are positive constants.

Suppose $D^{\mid}$denotes the region $0 \leq \alpha \leq \mathfrak{R}$ then, Eq. (3) - Eq. (5) have a unique solution if it is established that $\frac{\partial f_{1}}{\partial x_{j}}, i, j=1,2,3$ are continuous and bounded in $D^{\mid}$.

Using Eq. (3), we have the partial derivatives:

$\left|\frac{\partial f_{1}}{\partial U}\right|=\left|-\kappa V-\alpha_{1}\right|<\infty,\left|\frac{\partial f_{1}}{\partial E}\right|=|\gamma+\beta|<\infty,\left|\frac{\partial f_{1}}{\partial V}\right|=|-\kappa U|<\infty$

These partial derivatives exist, continuous and are bounded. For Eq. (4), we have: $\left|\frac{\partial f_{2}}{\partial U}\right|=|\kappa V|<\infty,\left|\frac{\partial f_{2}}{\partial E}\right|=\left|-\alpha_{2}-\gamma-\beta\right|<\infty,\left|\frac{\partial f_{2}}{\partial V}\right|=|\kappa U|<\infty$

and

$\left|\frac{\partial f_{3}}{\partial U}\right|=0<\infty,\left|\frac{\partial f_{3}}{\partial E}\right|=\left|\alpha_{2}+\gamma+\beta\right|<\infty,\left|\frac{\partial f_{3}}{\partial V}\right|=|-\delta|<\infty$

Since all the partial derivatives exist and are finite (bounded and defined), the solutions of the system of equations exist and are unique in $\Re^{3}$. This completes the proof.

Theorem 2: The region of attraction for the human compartments of the model represented by Eq. (3) and Eq. (4) is given by $\Gamma=\left\{(U, E): 0 \leq U+E \leq \frac{\pi+\omega}{m}\right\}$,

where $m=\min \left(\alpha_{1}, \alpha_{2}\right)$ and it attracts every solution in the interior of the positive octant. 
Proof:

Eq. (3) + Eq. (4) $\Rightarrow$

$\frac{d}{d t}(U(t)+E(t))=\pi-\alpha_{1} U(t)-\alpha_{2} E(t)+\omega \Rightarrow$

$\frac{d}{d t}(U(t)+E(t)) \leq \pi+\omega-m(U(t)+E(t))$

where $m=\min \left(\alpha_{1}, \alpha_{2}\right)$.

By taking limit supremum,

$\limsup _{t \rightarrow 0}(U(t)+E(t)) \leq \frac{\pi+\omega}{m}$

This completes the proof.

Theorem 3: The solution of the vacancy compartment $V(t)$ is also positive since every initial condition to the variable is always nonnegative.

Proof:

$$
\begin{aligned}
& \frac{d V}{d t}=\alpha_{2} E(t)+\gamma \mathrm{E}(\mathrm{t})+\beta \mathrm{E}(\mathrm{t})-\delta \mathrm{V}(\mathrm{t})+\phi \Rightarrow \\
& \frac{d V}{d t} \geq-\delta V(t) \Rightarrow \\
& \frac{d V}{V(t)} \geq-\delta d t \Rightarrow \\
& \int \frac{d V}{V} \geq-\int \delta d t
\end{aligned}
$$

Using the separation of variable method and applying the initial condition, we obtain

$$
\mathrm{V}(t) \geq V_{0} e^{-\delta t} \geq 0 \text {. }
$$

Since $e^{n}$ is always positive for every real value of $n$ then, the solution of $V(t)$ is always positive.

This completes the proof. 


\section{Model Analysis}

\section{Equilibria}

The model system (2) has an unemployment-free equilibrium, $F_{0}$ which is derived by reducing all the unemployment terms and the RHS of the model to zero. The result is obtained as:

$$
F_{0}=\left(\mathrm{U}^{0}, \mathrm{E}^{0}, V^{0}\right)=\left(0, \frac{\omega}{\alpha_{2}+\gamma+\beta}, \frac{\phi+\omega}{\delta}\right)
$$

Stability Analysis of the Unemployment-Free Equilibrium, $F_{0}$

Theorem 4: The unemployment-free equilibrium of the model is locally asymptotically stable if all the eigenvalues of the variational matrix of the system (2) are negative.

Proof: The variational matrix of the system (2) at the unemployment-free equilibrium is obtained as

$$
J\left(F_{0}\right)=\left(\begin{array}{ccc}
\frac{-\kappa}{\delta}(\phi+\omega)-\alpha_{1} & (\beta+\gamma) & 0 \\
\frac{\kappa}{\delta}(\phi+\omega)+\alpha_{1} & -\left(\alpha_{2}+\beta+\gamma\right) & 0 \\
0 & \left(\alpha_{2}+\beta+\gamma\right) & -\delta
\end{array}\right)
$$

Eq. (8) has the characteristic equation

$$
p_{0} \lambda^{3}+p_{1} \lambda^{2}+p_{2} \lambda+p_{3}=0
$$

where,

$$
\left.\begin{array}{l}
p_{0}=1 \\
p_{1}=\frac{\kappa}{\delta}(\phi+\omega)+\alpha_{1}+\alpha_{2}+\beta+\gamma+\delta \\
p_{2}=\frac{\kappa}{\delta}(\phi+\omega)\left(\alpha_{2}+\delta\right)+\alpha_{1} \delta+\left(\alpha_{1}+\delta\right)\left(\alpha_{2}+\beta+\gamma\right) \\
p_{3}=\kappa \alpha_{2}(\phi+\omega)+\alpha_{1} \delta\left(\alpha_{2}+\beta+\gamma\right)
\end{array}\right\}
$$

Using Routh-Hurtwitz stability criteria as in Galindro and Torres (2018), the unemployment free equilibrium of the model is locally asymptotically stable if the conditions $p_{1}>0, p_{3}>0$ and $p_{1} p_{2}-p_{3}>0$ are satisfied in Eq. (9). This is the necessary and sufficient condition for all the roots of Eq. (9) to have negative real parts which imply stable equilibrium. Obviously, $p_{1}>0$ and $p_{3}>0$ are satisfied 
since all the model parameters are non-negative. Therefore, the unemployment free equilibrium of the model system (2) is stable if $p_{1} p_{2}-p_{3}>0$.

\section{Results and Discussion}

Unemployment-free equilibrium is the equilibrium point in the absence of unemployment. It is a stage when a society attains full employment. At this point, it is assumed that nobody is unemployed in society. In reality, full employment is only possible in theory but not realistic in practice as some individuals may decide to be voluntarily unemployed regardless of the presence of employment. Even in a very buoyant economy like that of the United Arab Emirate and Qatar, the unemployment rate is still greater than zero, 1.72 and 0.10 respectively (NBS 2018). The stability of the unemployment-free equilibrium implies that the unemployment rate is kept at bay while the instability of the unemployment-free equilibrium implies that the unemployment rate has gone out of hand.

The first two conditions of the Routh-Hurwitz stability criteria have already been met. In order to draw a conclusion as regards the stability or otherwise of the model, there is a need to verify the third condition. To come about this, the values in Table 3 are taken as the base for each parameter to evaluate the initial value of $p_{1} p_{2}-p_{3}$ which is given in $\mathrm{S} / \mathrm{No} 1$ of Table 4 . The values of $\alpha_{2}, \kappa$ and $\phi$ are then varied to investigate the effect of the adjustment in the statutory age of retirement on the stability nature of the model and the result is presented in Table 4. The result in Table 4 is then supported graphically in Figure 1.

Table 4. Stability Result of the Model

\begin{tabular}{|l|c|c|c|c|c|c|c|c|c|c|}
\hline S/No & $\alpha_{1}$ & $\alpha_{2}$ & $\beta$ & $\kappa$ & $\phi$ & $\omega$ & $\gamma$ & $\delta$ & $p_{1} p_{2}-p_{3}$ & Remark \\
\hline 1 & 0.04 & 0.05 & 0.0001 & 0.000009 & 0.007 & 0.0002 & 0.001 & 0.005 & 0.000 & Unstable \\
\hline 2 & 0.04 & 0.06 & 0.0001 & 0.00001 & 0.008 & 0.0002 & 0.001 & 0.005 & 0.000 & Unstable \\
\hline 3 & 0.04 & 0.07 & 0.0001 & 0.00002 & 0.009 & 0.0002 & 0.001 & 0.005 & 0.000 & Unstable \\
\hline 4 & 0.04 & 0.08 & 0.0001 & 0.00003 & 0.01 & 0.0002 & 0.001 & 0.005 & 0.000 & Unstable \\
\hline 5 & 0.04 & 0.09 & 0.0001 & 0.00004 & 0.02 & 0.0002 & 0.001 & 0.005 & 0.001 & Stable \\
\hline 6 & 0.04 & 0.1 & 0.0001 & 0.00005 & 0.03 & 0.0002 & 0.001 & 0.005 & 0.001 & Stable \\
\hline 7 & 0.04 & 0.2 & 0.004 & 0.00006 & 0.04 & 0.0002 & 0.001 & 0.005 & 0.002 & Stable \\
\hline 8 & 0.04 & 0.3 & 0.005 & 0.00007 & 0.05 & 0.0002 & 0.001 & 0.005 & 0.005 & Stable \\
\hline 9 & 0.04 & 0.04 & 0.005 & 0.000008 & 0.006 & 0.0002 & 0.001 & 0.005 & 0.000 & Unstable \\
\hline 10 & 0.04 & 0.03 & 0.005 & 0.000007 & 0.005 & 0.0002 & 0.001 & 0.005 & 0.000 & Unstable \\
\hline 11 & 0.04 & 0.02 & 0.005 & 0.000006 & 0.004 & 0.0002 & 0.001 & 0.005 & 0.000 & Unstable \\
\hline 12 & 0.04 & 0.01 & 0.005 & 0.000005 & 0.003 & 0.0003 & 0.001 & 0.005 & 0.000 & Unstable \\
\hline
\end{tabular}


Figure 1. Possible Employment Situation in Nigeria in a Century

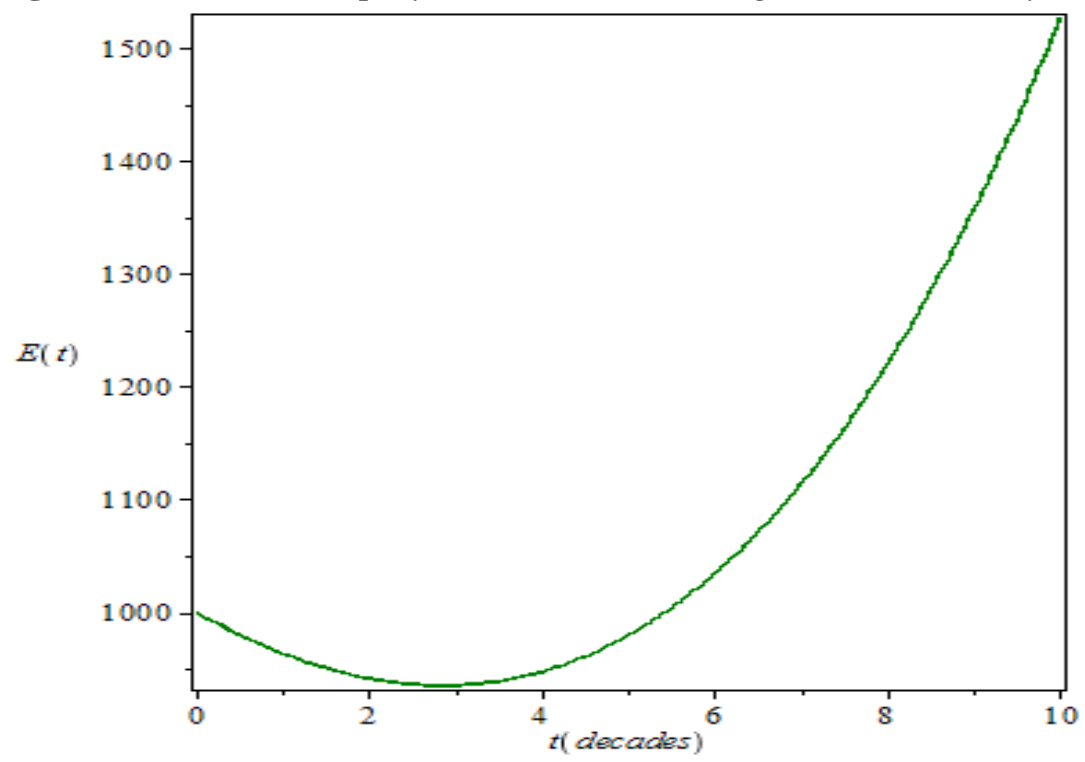

The current statutory age of retirement in Nigeria is 60 years. Generally, an increase in the rate of retirement which may be facilitated through a reduction in the statutory age of retirement will raise the rates at which new vacancies are being created and at the same time, the rates at which the unemployed individuals are becoming employed. On the other hand, a decrease in the rate of retirement which may be brought about by an increase in the statutory age of retirement will limit the rates at which new vacancies are being created and the rate at which the unemployed people are becoming employed. This is corroborated in Table 4. As an increase in the retirement rate $\left(\alpha_{2}\right)$ is accompanied by the simultaneous increase in the vacancies $(\phi)$ and the movement rate from the unemployed class to the employed class $(\kappa)$, the model is at start, unstable (S/No $2-\mathrm{S} / \mathrm{No} 4$ in Table 4) but finally reaches the stable region (S/No $5-\mathrm{S} / \mathrm{No} 8$ in Table 4). On the other hand, as a decrease in the retirement rate is followed by the corresponding decrease in the vacancies and the movement rate from the unemployed class to the employed class, the model continues to be unstable (S/No $9-$ S/No 12 in Table 4).

The implication of the result is that the current proposal of the increase in the statutory age of retirement in Nigeria is not only suicide but evil to the future of the younger and coming generations. As a good number of the working class in Nigeria are engaging in paid employment, increasing the statutory age of retirement will exacerbate the already worsen unemployment situation in the country. Besides, increasing the national statutory age of retirement above 60 years may have a decreasing effect on the national output as a good number of individuals above 60 years may have past their prime.

In Figure 1, if the current statutory age of retirement is increased then in 30 years time, more individuals will join and remain in the unemployed state but if the current statutory age of retirement is reduced then in 40 years time, more and more unemployed individuals will begin and continue to move to the employed 
state. Therefore, since the rates of increase in both labour force and unemployment is outrageous in Nigeria, encouraging the working class to go on voluntary retirement either by cash reward or by allowing them to replace themselves with an unemployed individual of their choice will reduce the rate of unemployment, put employment situation in the stable region (i.e. S/No 5 - S/No 8 in Table 4) and ensure better future for the younger and coming generations.

\section{Conclusions}

A nonlinear mathematical model for unemployment proposed in Munoli and Gani (2016) was extended to study the implication of the proposed rise in the statutory age of retirement on the unemployment situation in Nigeria by incorporating the rate at which the employment was being created and the tendency of upsurge in the population of the unemployed due to the influx of individuals who left their current job as a result of lack of job satisfaction. The solutions of the model were proved to exist, unique and positive. Equilibrium analysis was conducted and the unemployment-free equilibrium was obtained. Stability analysis of the unemployment-free equilibrium was also performed and the numerical simulation was carried out to verify the analytical results. The results of the simulation were finally discussed.

\section{References}

Adelowokan OA, Maku OE, Babasanya AO, Adesoye AB (2019) Unemployment, poverty and economic growth in Nigeria. Journal of Economics and Management. 35(1): 4-11.

Amin R (2019) Mathematical model of crime and unemployment. International Journal of Engineering Research \& Technology 8(9): 33-41.

Aminu A (2019) Characterising graduate unemployment in Nigeria as education-job mismatch problem. African Journal of Economics Review 7(2): 113-130.

El Fadily S, Kaddar A (2019) Modelling and mathematical analysis of labour force evolution. Hindawi Modelling and Simulation in Engineering. DOI: http://doi.org/ $10.1155 / 2019 / 2562468$

Galindro A, Torres DFM (2018) A simple mathematical model for unemployment: a case study in Portugal with optimal control. Statistics, Optimization and Information Computing 6(Apr): 116-129.

Harding L, Neamtu M (2018) A dynamic model of unemployment with migration and delayed policy intervention. Computational Economics 51(3): 427-462. DOI: 10.1007/s10614-016-9610-3.

Kazeem AB, Alimi SA, Ibrahim MO (2018) Threshold parameter for the control of unemployment in the society: mathematical model and analysis. Journal of Applied Mathematics and Physics 6 (Dec): 2563-2578. DOI: 10.4236/jamp.2018.612214.

Misra AK, Singh AK (2011) A mathematical model for unemployment. Nonlinear Analysis Real World Application 12(1): 128-136.

Misra AK, Singh AK (2013) A delay mathematical model for the control of unemployment. Differential Equation Dynamical System 21(3): 291-307. 
Munoli SB, Gani S (2016) Optimal control analysis of a mathematical model for unemployment. Optimal Control Application Methods 37(Nov): 798-806.

National Bureau of Statistics-NBS (2018) Labour force statistics-volume1: unemployment and underemployment report. Retrieved from: https://nigerianstat.gov.ng/down load/694. [Accessed 3 January 2019].

Nikolopoulos CV, Tzanetis DE (2003) A model for housing allocation of a homeless population due to natural disaster. Nonlinear Analysis 4(Oct): 561-579.

Sirghi N, Neamtu M, Deac DS (2014) A dynamic model for unemployment control with distributed delay. Mathematical Methods in Finance and Business Administration 12 (Apr): 42-48.

Teixeira GS, Neto GB, Leivas PHS (2020) Evidence on rule manipulation and moral hazard in Brazilian unemployment insurance program. International Journal of Social Science Studies 8(1): 67-78.

Yasin K, Gachunga MJ (2019) An analysis of the impact of unemployment on economic growth in Kenya. International Journal of Business Marketing and Management 4(4): 52-57. 
